\title{
Analysis of the Wider Economic Impact of a Transport Infrastructure Project Using an Integrated Land Use Transport Model
}

\author{
Wanle Wang ${ }^{1,2,3,4} \mathbb{1}$, Ming Zhong ${ }^{1,2,3, *}$ and John Douglas Hunt ${ }^{1,2,3,5}$ \\ 1 National Engineering Research Center for Water Transportation Safety, 1040 Heping Avenue, \\ Wuchang District, Wuhan 430063, China; wlwang@whut.edu.cn (W.W.); jdhunt@ucalgary.ca (J.D.H.) \\ 2 Intelligent Transport Systems Research Center, Wuhan University of Technology, 1040 Heping Avenue, \\ Wuchang District, Wuhan 430063, China \\ 3 Engineering Research Center for Transportation Safety, Ministry of Education, 1040 Heping Avenue, \\ Wuchang District, Wuhan 430063, China \\ 4 College of Air Traffic Management, Civil Aviation University of China, 2898 Jinbei Road, Dongli District, \\ Tianjin 300300, China \\ 5 Department of Civil Engineering, University of Calgary, 2500 University Drive NW, \\ Calgary, AB T2N 1N4, Canada \\ * Correspondence: mzhong@whut.edu.cn; Tel.: +86-27-5085-3212
}

Received: 20 October 2018; Accepted: 4 January 2019; Published: 12 January 2019 updates

\begin{abstract}
Major cities in developing countries are undergoing massive transportation infrastructure construction, which has significant impacts on the land use and economic activities in these cities. Standard Cost-Benefit Analysis (CBA) is applied to quantify the user benefits of transport projects, but does not provide an answer as to who will obtain the benefits and who will lose out and excludes the calculation of Wider Economic Impacts (WEIs) which can sometimes be large and hardly negligible. This paper introduces thoughts and experiences obtained through the design and development of an integrated land use transport model for the assessment of the WEI of a transport infrastructure project. The development and application of such an integrated model for WEI analysis should help decision-makers understand not only the "direct or immediate" impact of transport infrastructure on mobility, but also those "indirect or long-term" impacts on the distribution patterns of economic activities, corresponding land use, and resulting urban structure.
\end{abstract}

Keywords: wider economic impacts; integrated land use transport model; distributional effect; agglomeration effect; metro line project

\section{Introduction}

For the past two decades, the study of a range of Wider Economic Impacts (WEIs) or Wider Economic Benefits (WEBs) associated with transport infrastructure projects has caught the attention of many researchers. Researchers argue that large transport projects, together with the appropriate policies, can generate additional benefits over the user benefits calculated in the traditional Cost-Benefit Analysis (CBA) method. The assessment of WEIs has been included in the guidelines for transport appraisal in many countries, e.g., the U.K., the Netherlands, and so on [1,2]. Nowadays, major cities in developing countries are undergoing massive transportation infrastructure construction, which has significant impacts on the land use and economic activities in these cities. To understand the wider economic impacts brought about by transport projects, especially by the land use change response, and the distribution of such benefits, an integrated land use transport model is an urgent need. 
PECAS stands for the Production, Exchange, and Consumption Allocation System (PECAS), which is one of the integrated land use transport modeling frameworks recently developed. Built upon the theories of and experiences with its pioneers MEPLAN [3] and TRANUS [4], the PECAS framework simulates the spatial economic systems under consideration and has been enhanced with several distinct features such as enhanced representation of socioeconomic systems through a social accounting matrix and microsimulation-based space development [5]. Over the last 15 years, the PECAS framework has been implemented in different locations worldwide, including Oregon (statewide) [6,7], California (statewide) [8], Atlanta [9], San Diego, Los Angeles, and San Francisco, USA; City of Edmonton, Province of Alberta, Canada [5]; Caracas, Venezuela [10]; and Mumbai, India [11].

This paper introduces thoughts and experiences obtained through the design and development of an integrated land use transport model for the assessment of the wider economic impacts of a transport infrastructure project, especially the agglomeration effect. An integrated land use transport model for the City of Wuhan, China, which is developed based on a PECAS model, is used to analyze the agglomeration effect of a metro line construction project. A large number of data have been assembled to develop the model, including census population/employment (2010), a household travel survey (2008), Yearbooks (2008 onwards), input-output tables (2007 onwards), land use (current and zoned) and space quantities at the traffic analysis zone (TAZ) level (2012), space rent/sale price, and household financial survey results. The development and application of such an integrated model for WEI analysis should help decision-makers understand not only the "direct or immediate" impact of transport infrastructure on mobility, but also those "indirect or long-term" impacts on the distribution patterns of economic activities, corresponding land use, and resulting urban structure.

The paper is organized as follows: After a literature review and brief introduction of one of the WEIs of a transport project-the agglomeration effect-the PECAS framework and the Wuhan PECAS model are introduced as our methodology. Then, the capability of the model to measure the agglomeration effect of the project is demonstrated with a case study. The study results are presented in the following section, where a discussion is also provided. Finally, our conclusions and recommendations are given.

\section{Literature Review}

Traditionally, the "rule of half" (RoH) method, which is based on the consumer surplus concept, is applied in CBA for a transport project appraisal. Many studies have explained the details of this method [12-14]. In welfare economics, the level of welfare is measured by adding up the amounts of money that people are willing to pay for goods and services [12]. As shown by the demand function in Figure 1, suppose with a transport infrastructure improvement, the generalized cost $(G C)$ decreases from $G C^{0}$ to $G C^{1}$; the travel demand will increase from $T^{0}$ to $T^{1}$ accordingly. Consumers who have already agreed to pay $\left(G C^{0}\right)$ now pay $G C^{1}$, generating a welfare change represented by the area $\mathrm{B}$. Now new consumers pay for the trip at a lower cost, whose welfare change can be approximated by the "rule of half": $1 / 2\left(T^{1}-T^{0}\right)\left(G C^{1}-G C^{0}\right)$, which is shown by the area A. The total change in consumer surplus is $\mathrm{A}+\mathrm{B}$. 


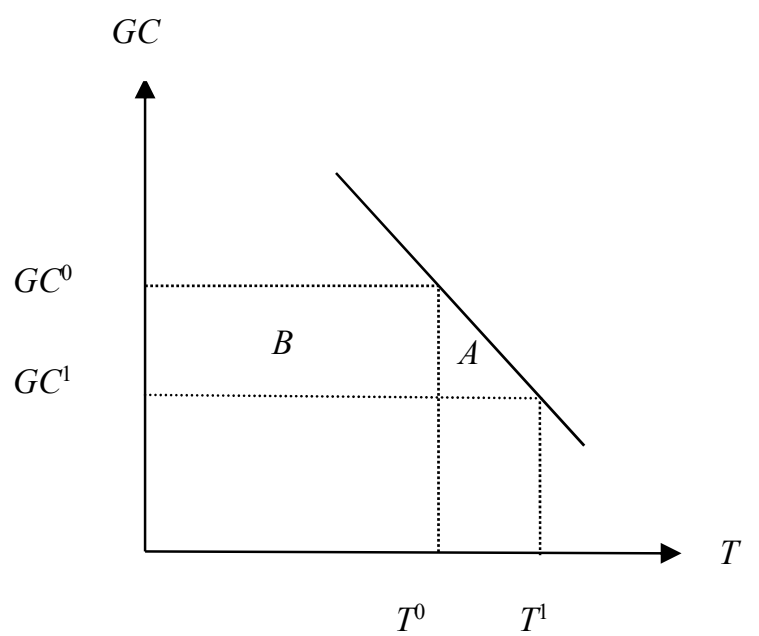

Figure 1. "Rule of half" (RoH) method for user benefit assessment.

With the introduction of the logsum method, researchers began to test the capability of the logsum method as an evaluation tool. De Jong et al. reported the use of the logsum method as an evaluation tool and suggested replacing CBA with logsum, though the authors mentioned that more research on it should be carried out [12]. Zondag explained that the logsum method can take into account the benefits induced by the change of attractiveness of the location and the traffic distribution, while the rule of half method can only estimate benefits for the origin-destination combinations in terms of a generalized cost change [15]. Ma et al. proposed a three-level nested logit model for travel decisions combining destination choice, mode choice, and route choice, and estimated the traveler benefits with the logsum difference [14]. They found that the benefits estimated with the logsum method are normally less than those with the RoH method.

There is a great deal of research focusing on the impact assessment of rail transit on land use, property value, residential location choice, and the urban structure. Cevero and Landis studied the effect of the Bay Area Rapid Transit (BART) system of the San Francisco city on the urban form [16]. They found that the impact of the system was limited to the city center of San Francisco and Oakland and a few suburban stations. The land use of the other areas remained almost constant due to the opposition of the inhabitants or the stagnant situation of the real estate market of the area. They concluded that the construction of the BART system itself would not bring significant changes to land use; however, under proper conditions, the system may contribute to land use change. Focusing on rail transit, Pan et al. studied its impacts on land use, residential location choice, and spatial structure [17-19]. Dube et al. assessed the impact of the opening of a commuter rail from the center of the Montreal City to its southern suburban areas [20]. In their study, they applied the difference-in-differences (DID) estimator to the Hedonic price model and the data of housing sales (1992-2009). They concluded that the opening of the railway increased the location utility of the housing near the stations. Kay et al. studied the residential property valuations near eight stations of the Transit-Oriented Development (TOD) system [21]. They analyzed the relationship between the median property value and the distance to the TOD stations and other stations with direct connections with New York City. They found that even though the mixed land use brought about by the TOD system increased the housing value around the stations, proximity to the stations with direct connections with New York City led to higher relative property valuations, which indicated that the travel destination is also a very significant factor. Wu et al. categorized the impact of rail transit on residential property appreciations into two types, transport benefit and agglomeration benefit, which were defined by two different accessibility metrics [22]. They analyzed the relationship between accessibility improvement and housing value increase. According to their study, there exists a linear relationship between the accessibility improvement by rail transit and the house value increase. 
The Standing Advisory Committee on Trunk Road Appraisal (SACTRA) elaborated on the relationship between transport and economy and raised the questions of imperfect competition widely existing in reality and the completeness of the economic efficiency appraisal of transport projects [23]. The integrated land use transport interaction (LUTI) model and computable general equilibrium (CGE) model are recommended as the two modeling techniques which hold the greatest possibility for incorporating wider economic benefits into a transport appraisal package. CGE models have their origins in economic models of trade and take spatially differentiated firms and markets, rather than places, as the basic units of analysis. Compared to the CGE models, LUTI models focus on the interactions between economic units located in specific places. The Lowry model, developed in 1964, is seen as the classic LUTI model and is the first operational framework that can explicitly consider the interactions between land use and transportation [24]. In the following years, many different types of LUTI models were developed [25-28]. Feldman et al. implemented a LUTI model (DELTA) for the assessment of the wider economic benefits of a set of transport schemes, following the methods recommended by the U.K. Department for Transport (DfT) [29]. They concluded that the analysis of these effects can have a major impact on the appraisal of transport strategies. Rodier applied the PECAS model (an integrated land use transport model) to assessing the wider impacts of land use and transportation plans, including wages, rents, productivity, and/or changes in consumer surplus [30].

One of the WEIs highlighted in the literature is referred to as the agglomeration effect, which arises when a transportation system investment allows the market scale to be increased, providing a larger pool of intermediate inputs, labors inputs, knowledge, and other resources for firms [31-33]. It is widely recognized that economic density - the clustering of economic activities-has a positive impact on productivity [34,35]. Transport infrastructure improvement enables a decrease of time and cost for firms, workers, and consumers, thus resulting in a change in productivity. In the short run, when there are improvements to a transport system, travel behavior responses will surely follow, such as the change of modes or time of day of travel. In the long run, change to the transport supply brings changes to accessibility and, thus, the attraction of different zones for housing and working. However, as we are aware, this has never been explored with a LUTI model in a developing country's context.

When it comes to estimation of the agglomeration effect, two steps are usually followed: the first is to construct a measure of effective density to represent agglomeration, and the second is to link productivity to this measure [34,35]. For the construction of the effective density, usually a metric combining employment and the weight between the two zones is used. However, there are different arguments about the use of time or distance as the weight. Graham used straight-line distances in effective density calculations rather than network distances, times, or costs, because the existing transport network and service are in part dependent on transport demand, which is in turn dependent on the level of economic activity and productivity in a given location. However, he also stated that the more direct way to incorporate transport costs or times into estimates of local economic mass is to base these estimates on existing transport costs or times rather than geographic distances.

In the second step, the agglomeration metric is linked to productivity. At this step, an econometric study is often required to estimate the elasticity of productivity with respect to agglomeration. For the estimation of agglomeration elasticities for different sectors, many efforts have been made. Generally, different elasticities apply to different industries in different countries. In the U.K., the service sector has a higher agglomeration elasticity than does the manufacturing sector. Graham used firm-level data to estimate the elasticity of productivity with respect to agglomeration [34]. Some results of his studies are adopted by the U.K. Department for Transport (DfT) [1]. According to the relationship between labor productivity represented by wage and accessibility to employment, Hensher et al. estimated the agglomeration elasticities for different industries in Sydney and, further, the WEI of a rail project [33]. However, due to the lack of data, some research has had to determine the most reasonable elasticities for different industries from a literature review [36]. In China, the relationship between agglomeration and productivity has been explored [37,38]; however, no specific agglomeration elasticities for different industries are widely recognized and recommended. 
As to the magnitude of the estimated agglomeration benefits, Hensher et al. concluded that the WEI of the NWRL project (North-West Rail Link project in Sydney) amounts to a $17.6 \%$ markup per year over conventional benefits (\$4.486 million/\$25.486 million as at 2006) [33]. In the WEI assessment of the Crossrail project in the U.K., the agglomeration effects amounted to $30 \%$ of the total business and commuting time and reliability benefits in a conventional appraisal [39]. It is estimated that the Crossrail project will enable 33,000 workers to relocate to central London by 2027, and they will be more productive than otherwise [39]. Normally, agglomeration benefits are assessed for intra-urban schemes. To test the agglomeration benefits of inter-urban investments, Graham and Melo estimated the decay of the agglomeration effect with time in the context of a high-speed rail [40]. They found that the order of magnitude of agglomeration benefits corresponding to $25 \%$ and $50 \%$ increases in travel speeds was small.

After examining how 23 industrialized countries treat WEIs in transport appraisals, Wangsness et al. [2] concluded that even though the concept of WEIs has matured over the last decade, there is still relatively little consensus on the magnitude and relevance of WEIs, and further research is needed to better understand the nature of WEIs. Our paper aims to offer some insights into the area from a developing country's perspective.

\section{Methods}

\subsection{Agglomeration Effect Estimation}

A metric of effective density to measure agglomeration is defined in references [34,35] and is basically a measure of the accessibility of zone $i$ to jobs in all the destination zones:

$$
A_{i}=\sum_{j} f\left(d_{i j}\right) \cdot E_{j}
$$

where $A_{i}$ represents the effective density of zone $i$; $E_{j}$ is the employment of zone $j$; and $f\left(d_{i j}\right)$ is the weight, which can be a function of the distance, time, or generalized cost of traveling from zone $i$ to $j$. A transport improvement can change access to economic mass in two distinct ways. One is that it changes the levels of activity $E_{j}$ in each location, which is referred to as "dynamic clustering" and is associated with land use change. The other is the change of the matrix of distance $d_{i j}$ between locations, which is referred to as "static clustering" [35].

In the case study of this paper, the most conservative agglomeration elasticities for different industries are given according to research results in the literature [36] to exemplify the calculation of the agglomeration effect of a transport investment, as shown in Table 1.

Table 1. Agglomeration elasticity by industry.

\begin{tabular}{cc}
\hline Industry Sectors & Agglomeration Elasticity \\
\hline Agriculture-Operation & 0 \\
Agriculture-Office Support & 0 \\
Industry-Operation & 0.035 \\
Industry-Office Support & 0.035 \\
Transport and Utility-Operations & 0.044 \\
Transport and Utility-Office Support & 0.044 \\
Commerce-Service & 0.010 \\
Education and Research & 0.004 \\
Other Institutions (Health/Welfare/Entertainment/Sport/Culture) & 0.004 \\
Government Services & 0.004 \\
\hline
\end{tabular}


Finally, the equation for calculating the agglomeration effect of a project for the forecast year $f$ in an Alternative case (with investment, denoted by 1 ) with respect to a Reference case (without investment, denoted by 0 ) is given by [1]

$$
\begin{gathered}
W I_{i}^{k, f}=\left[\left(\frac{A_{i}^{1, k, f}}{A_{i}^{0, k, f}}\right)^{\rho^{k}}-1\right] \cdot G D P W_{i}^{0, k, f} \cdot E_{i}^{0, k, f} \\
W I^{f}=\sum_{i, k} W I_{i}^{k, f}
\end{gathered}
$$

where $W I_{i}^{k, f}$ represents the wider benefit of agglomeration for each location $i$ (TAZ used in transport modeling) and sector $k$ for the forecast year $f ; A_{i}^{1, k, f}$ and $A_{i}^{0, k, f}$ are the effective densities of location $i$ and sector $k$ in the Alternative case and Reference case, respectively; $\rho^{k}$ is the elasticity of productivity with respect to effective density for sector $k$; GDPW $W_{i}^{0, k, f}$ is the GDP per worker of location $i$ and sector $k$ in the Reference case; and $E_{i}^{0, k, f}$ is the total employment of location $i$ and sector $k$ in the Reference case.

\subsection{The PECAS Framework}

PECAS is a generalization of the spatial I/O modeling approach used in the MEPLAN and TRANUS land use transport modeling systems. Both the "integrated" structure and the "connected" structure can be set up in PECAS. In an integrated model, the land use component feeds the spatial distribution of flows of economic interactions between zones as origin and destination movements into the transport component, and the transport module performs the remaining steps. However, the transport component of a connected model performs the four classical steps, including trip distribution. Compared with a connected structure, the integrated option assures the best integration of the two components and avoids inconsistency in the use of an origin to destination (O-D) matrix. When a fully fledged, four-step model is in place, a connected structure can be easily set up to run the land use and transport models concurrently. An integrated structure can be developed over a long run when resources and opportunities permit. Depending on its design and purposes, the PECAS model usually consists of the following modules: Economy and Demographics Forecasting (ED module), Activity Allocation (AA module), Space Development (SD module), and the Transport model, as shown in Figure 2 [41]. The ED module is used to develop aggregate economic forecasts for the studied area. The AA module represents how activities locate within the space provided and how these activities interact with each other at a given time, which is an aggregate representation based on spatially disaggregated forms of extended input-output tables. The SD module represents the actions of developers in the provision of space where activities can locate. The Transport model represents the transport system connecting locations. The travel conditions-distances, costs, times, and associated disutilities by mode - for the movement of different commodities (services, goods, or labor) are how the transportation system influences the attractiveness of zones as locations for different activities. When a transport investment is made, the travel conditions will be changed, resulting in changes in the attractiveness of locations and the corresponding quantities of activities at them. 


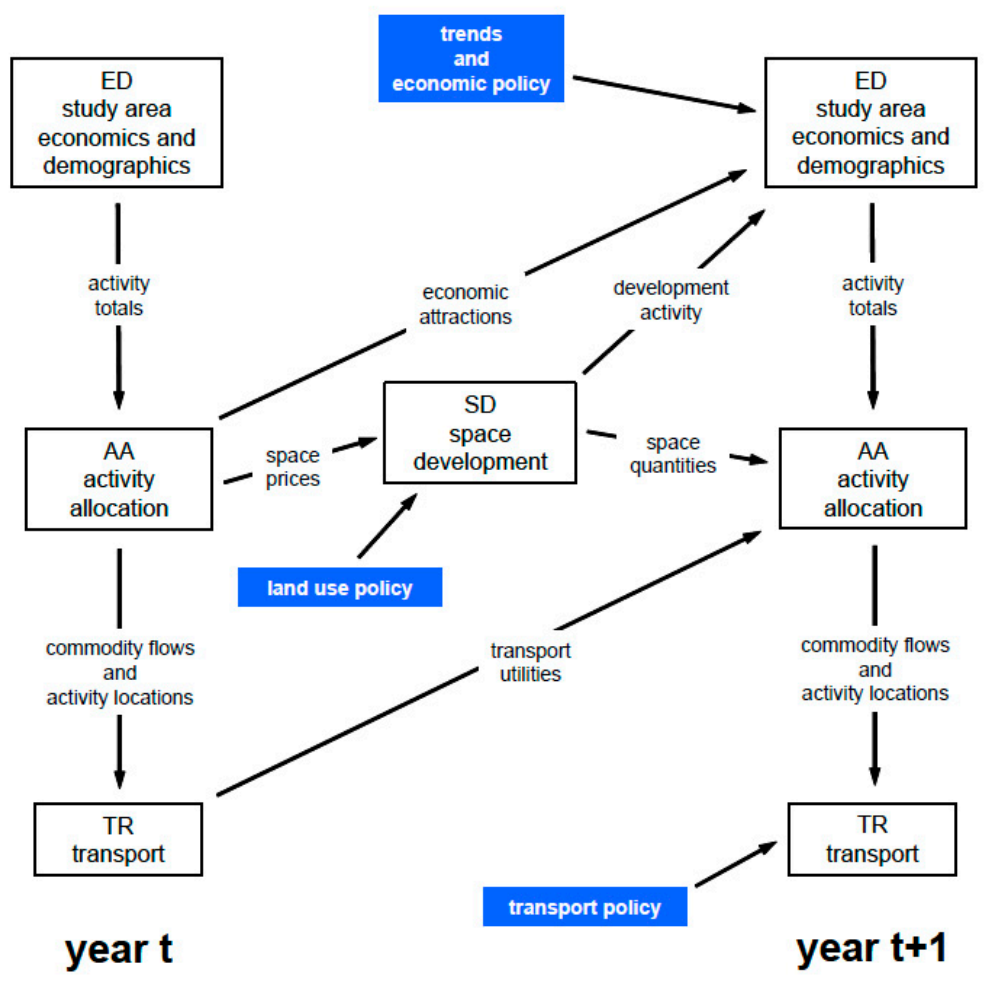

Figure 2. The Production, Exchange, and Consumption Allocation System (PECAS) framework.

The PECAS AA module applies three-level nested logit models to represent the choice of location, production-consumption options (called "technology"), and quantities of buying or selling of different activities at exchange locations, as shown in Figure 3.

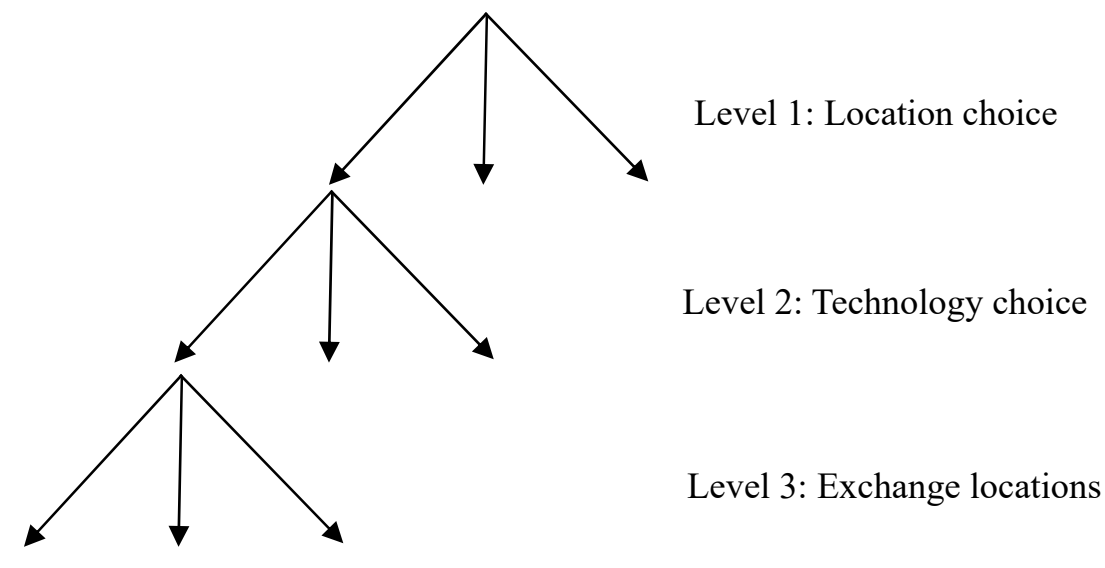

Figure 3. Nested logit model structure of the AA module.

At the top level, a quantity from each activity category (industries and households) is allocated to each location. Within each location, each activity is further allocated to different production and consumption options. At the lowest level, the produced commodities (goods, services, labor, and floor space) sold and the consumed commodities bought are allocated among exchange locations. At this level, both the selling utility and the buying utility are determined partly by the transport disutility. The lower-level utilities will finally determine the composite location utility of each activity. When the transport utility changes, the generalized cost of travel will change and the utility of locating an activity at different locations will change accordingly. Based on the quantity of the activity (unit: 10,000 yuan) at a location and the estimated coefficients of 10,000 yuan per employment for different activities, we can obtain the amount of labor (employment) required (consumed). 


\subsection{Wuhan PECAS Model}

The City of Wuhan, located in the central part of China and with an area of $8494 \mathrm{~km}^{2}$, is the capital of Hubei province, the largest city in Central China, and the largest transportation hub in China. The City of Wuhan is undergoing rapid economic and social development; therefore, a careful plan is required for a sustainable development. Integrated land use transport models, with their ability to simulate the impact of different policies on economic activities and land use, can be applied to facilitate the sustainable development of cities. Currently, a PECAS demonstration model is being developed for the City of Wuhan [42]. A large number of data items about the city have been assembled. At this stage, the joint AA-SD version of the Wuhan PECAS demonstration model is running and is subject to further calibration and validation.

After preprocessing the TAZ map data of Wuhan city, the zones located within the Third Ring Road and the ones located outside the Third Ring Road but with commercial and office buildings (identified from Point Of Interest (POI) data) are categorized as urban zones, and the rest are identified as rural zones. There are a total of 690 TAZs in the City of Wuhan, from which 399 urban zones and 291 rural zones were identified.

Figure 4 below shows the population and employment density by TAZ in Wuhan in 2008 (the base year). As can be seen from the figure, the employment of the city is more centralized than its population, with most employment allocated within the Third Ring Road of the city.

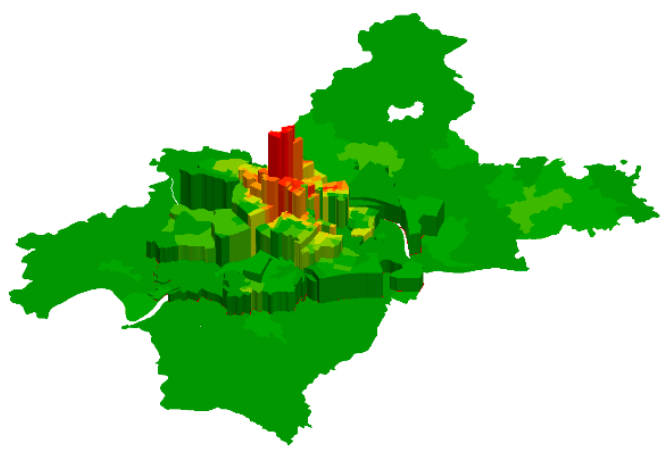

(a)

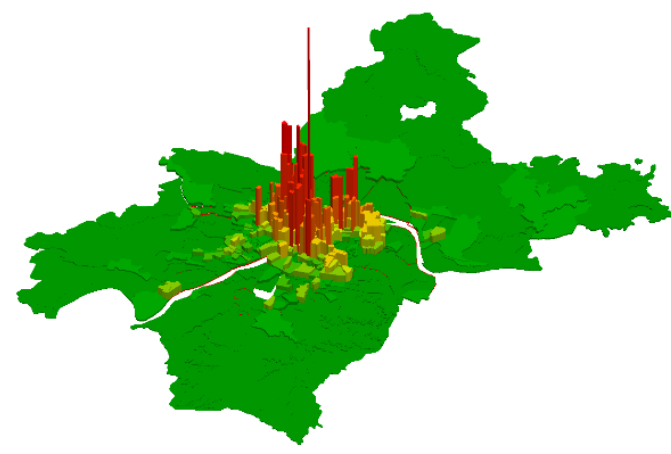

(b)

Figure 4. Population density (a) and employment density (b) by TAZ in 2008.

The 14 sectors considered in the Wuhan PECAS demonstration model, including industry sectors and households, are shown in Table 2.

Table 2. Sectors and households considered in the Wuhan PECAS demonstration model.

\begin{tabular}{cc}
\hline Industry Sectors & Households \\
\hline Agriculture-Operation & Household-Urban \\
Agriculture-Office Support & Household-Rural \\
Industry-Operation & \\
Industry-Office Support & \\
Transport and Utility-Operations & \\
Transport and Utility-Office Support & \\
Commerce-Service & \\
Education and Research & \\
Other Institutions (Health/Welfare/Entertainment/Sport/Culture) & \\
Government Services & \\
Government Accounts & \\
Capital Accounts & \\
\hline
\end{tabular}

Figures 5-7 show some of the outputs from the Wuhan PECAS model. In Figure 5, the forecasted buying and selling quantities of the retail service labor by zone for a given year are shown. The red 
area for the Buying_Quantiy indicates the highest concentration of retail service labor. Figure 6 is the buying quantity of industrial commodities for an example zone for a given year.

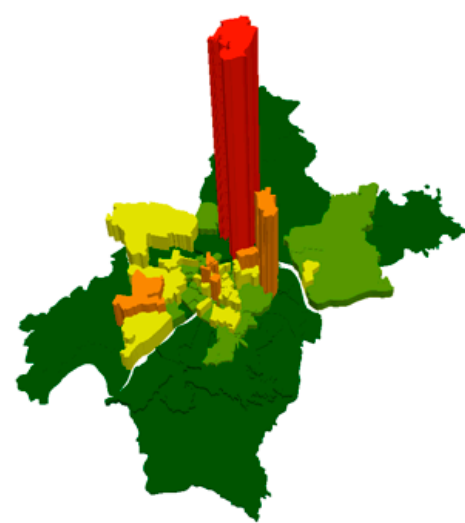

(a) Buying_Quantity

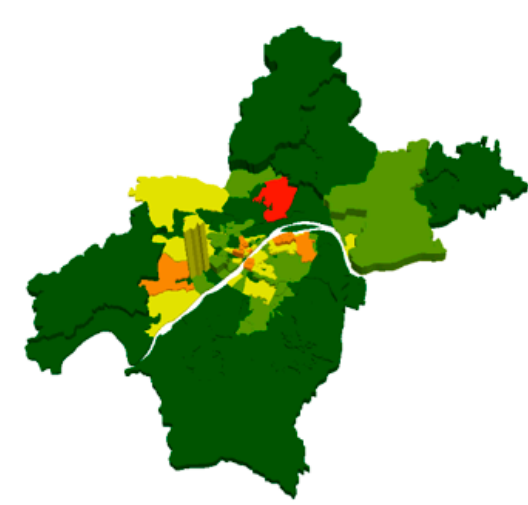

(b) Selling_Quantity

Figure 5. Forecasted buying and selling quantities by zone for the commodity of retail service labor for a given year.

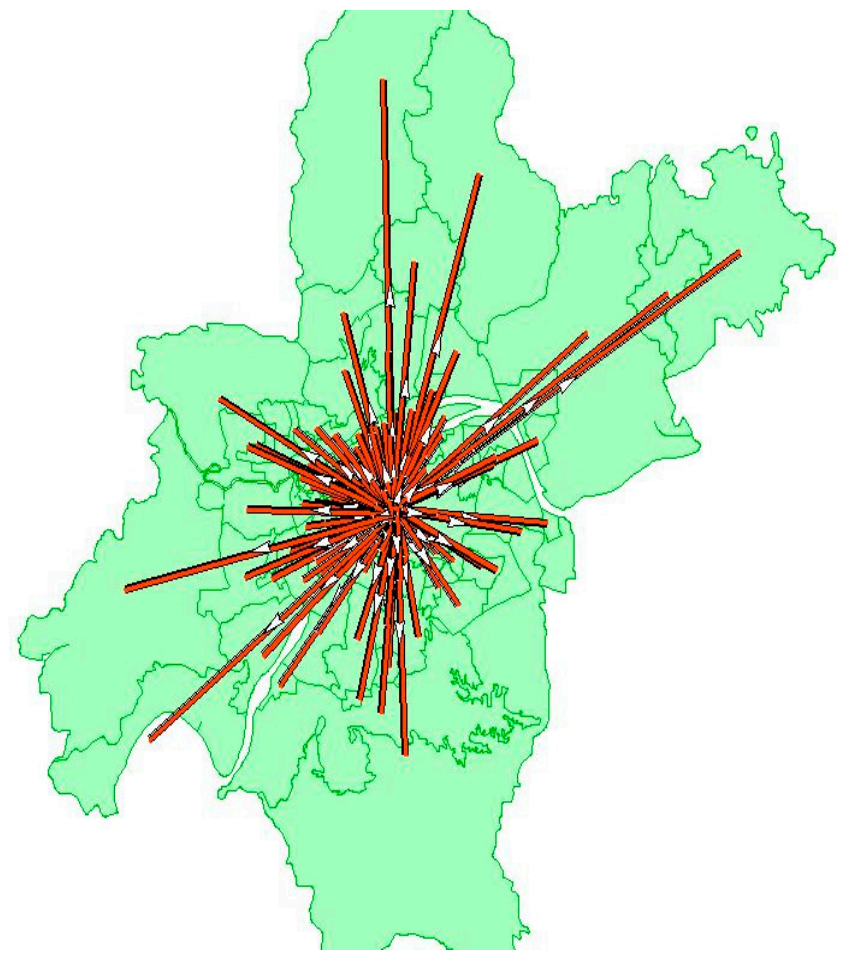

Figure 6. Forecasted buying quantity of industrial commodities for an example zone for a given year. 


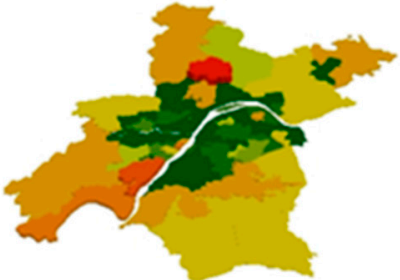

2008

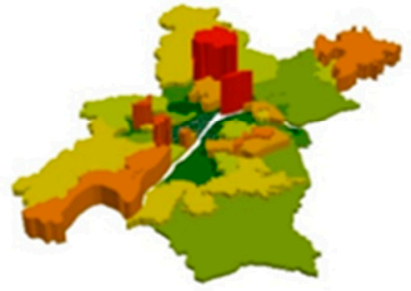

2028

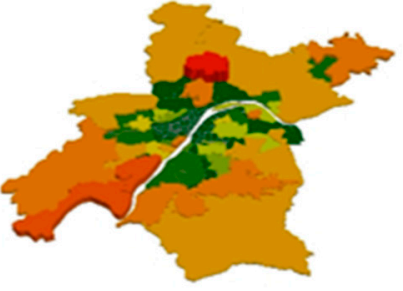

2012

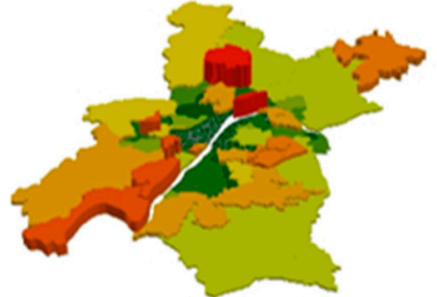

2020

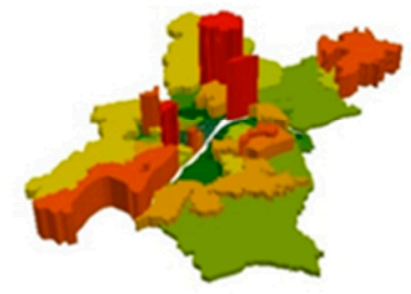

2035

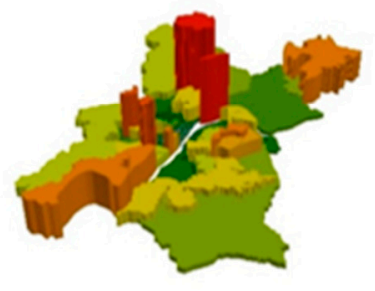

2038

(a)
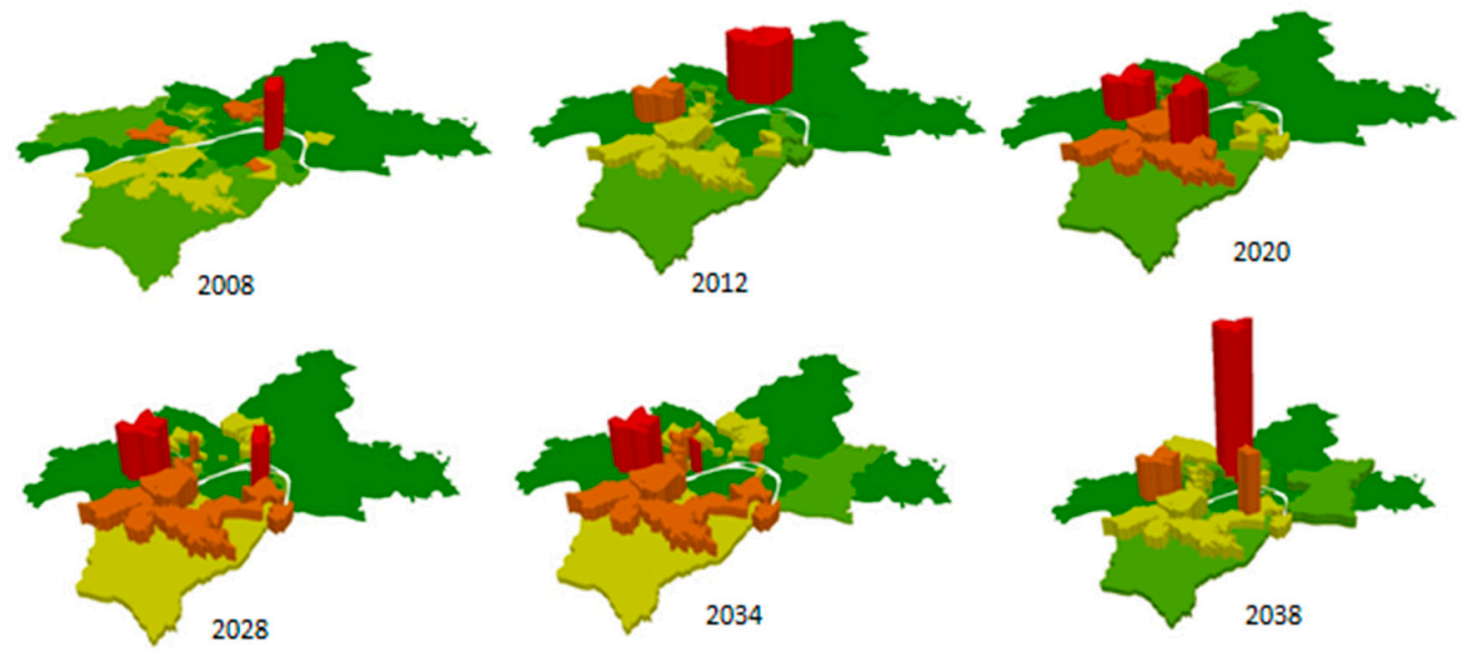

(b)

Figure 7. (a) Forecasts of agriculture operation activity for different years in different zones; (b) Forecasts of developed office space quantities for different years in different zones.

Examples of the outputs from the AA module and the SD module of the Wuhan PECAS model are shown in Figure 7a,b. Figure 7a demonstrates the development of agriculture operation activity over different years in different zones. Figure $7 \mathrm{~b}$ demonstrates forecasts of developed office space quantities for different years in different zones.

\section{Results}

To illustrate the above analysis and the calculation of the agglomeration effect, we take the construction of Metro Line 2 of Wuhan City as an example. The transport infrastructure improvement 
will lead to changes in work location and residential location choices in the long run, which can be demonstrated by an integrated land use transport model like PECAS. Here we use a time-dependent generalized cost and HBW (Home-based Work) with car trips for the calculation of effective density.

\subsection{Introduction to Metro Line 2}

The construction of the first phase of the Metro Line 2 project began in 2006, and the line was opened in 2013. It is the first metro line that crosses the Yangtze River, connecting the core economic area north of the river and that south of the river. From the north to the south, the line connects Changqing Garden residential block, Wangjiadun CBD, the core economic area north of the river, the core economic area south of the river, and the Donghu High-Tech development zone. The first phase of the project is $27.7 \mathrm{~km}$ long with 21 stations, taking about $50 \%$ of the passenger traffic crossing the river on public transit. It is predicted to encourage the development of residential space in Changqing Garden block and the Donghu High-Tech development zone. The airport line (north extension) of the Metro Line 2 was opened in 2016, reducing the traveling time to the Wuhan Tianhe International Airport. It is $19.8 \mathrm{~km}$ long with seven stations. The first phase of the project plus the north extension of Metro Line 2 is shown with seven representative stations in Figure 8. The designators for the TAZs where the seven representative stations are located are shown in Table 3. With the Metro Line 2, the access time, egress time to/from the stations in the affected zones, and in-vehicle time for travel between zones will be changed.

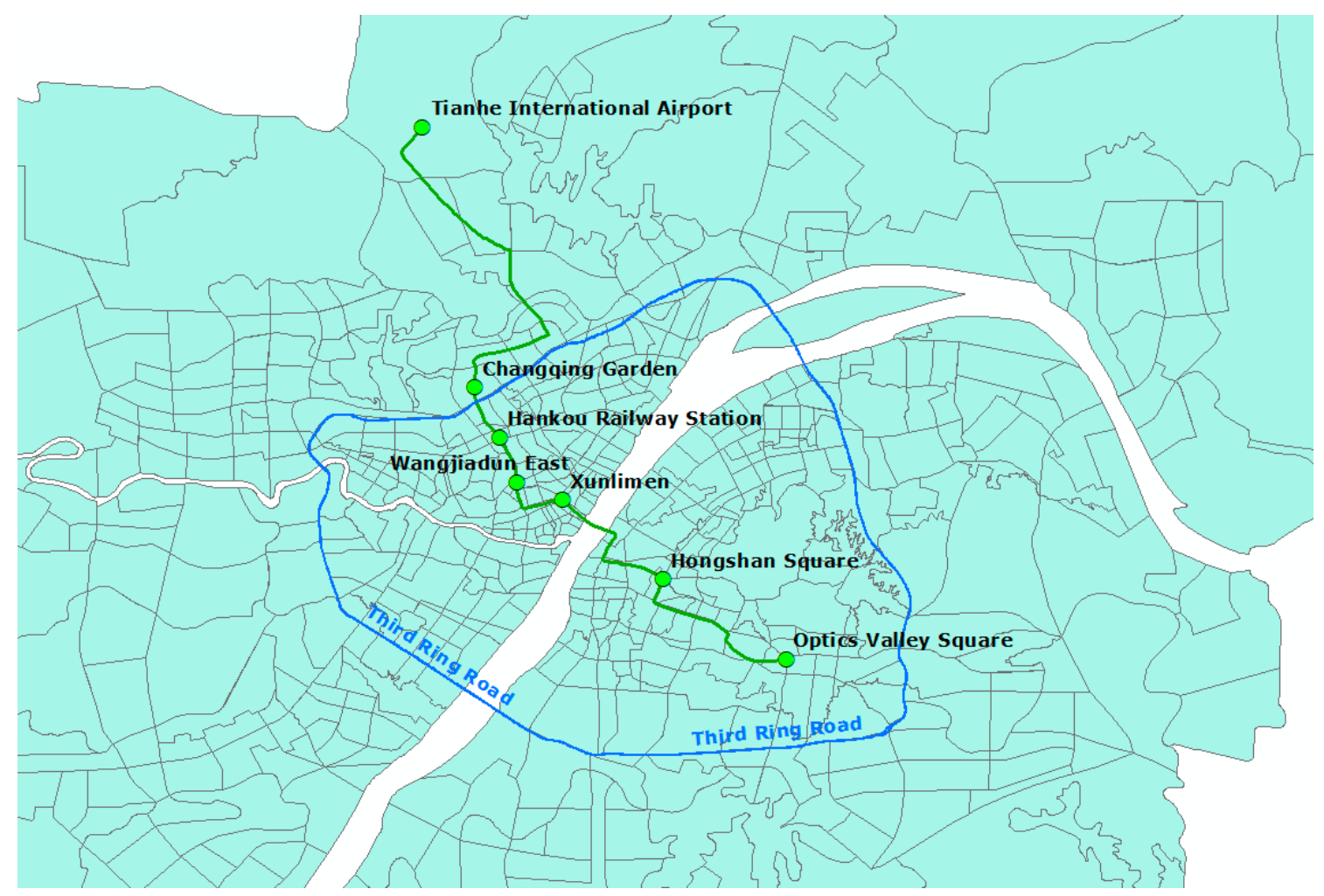

Figure 8. Metro Line 2 on TAZs of Wuhan City. 
Table 3. TAZ no. of the seven representative stations.

\begin{tabular}{ccc}
\hline Zone No. & Representative Station & Area $\mathbf{( k m}^{\mathbf{2}} \mathbf{~}$ \\
\hline 1518 & Tianhe International Airport & 88.657 \\
1443 & Changqing Garden & 5.135 \\
1207 & Hankou Railway Station & 0.839 \\
1214 & Wangjiadun East & 0.656 \\
1229 & Xunlimen & 0.449 \\
3140 & Hongshan Square & 2.332 \\
3225 & Optics Valley Square & 1.718 \\
\hline
\end{tabular}

The base year for the assessment is 2008, with all monetary units estimated at constant 2008 yuan. The assessment period is from 2016 to 2030. The agglomeration effect of Metro Line 2 is analyzed at the TAZ level, which can be aggregated for estimating total outcomes.

\subsection{Agglomeration Effects Estimation}

According to the analysis in Section 3.1, to measure the agglomeration effect of the Metro Line 2 project, the following parameters need to be determined: effective densities of location $i$ and sector $k$ in the Alternative case and Reference case, respectively; the elasticity of productivity with respect to the effective density for sector $k$; the GDP per worker of location $i$ and sector $k$ in the Reference case; and the total employment of location $i$ and sector $k$ in the Reference case. Among these, the calculation of the effective density is the main task, while the other parameters can be obtained from open public statistics or a literature review.

Based on the forecasted CPI (Consumer Price Index) growth rate, the salary growth rate, and the coefficients for observed 10,000 yuan per job in different industries in 2008, we obtained the result that in 2030, overall, there will be an addition of 3.4 million jobs. Figure 9 shows the changes in the total number of employment opportunities in the seven representative TAZs where the selected seven metro stations are located. The employment opportunities increase in all seven zones except for Zone 1518 (losing 11,027 jobs, a $17.1 \%$ decrease). Of all the six zones with increasing employment opportunities, Zone 1443 increases the most (gaining 3241, a 20.3\% increase), while Zone 1214 increases the least (gaining 61 , a $1.2 \%$ increase).

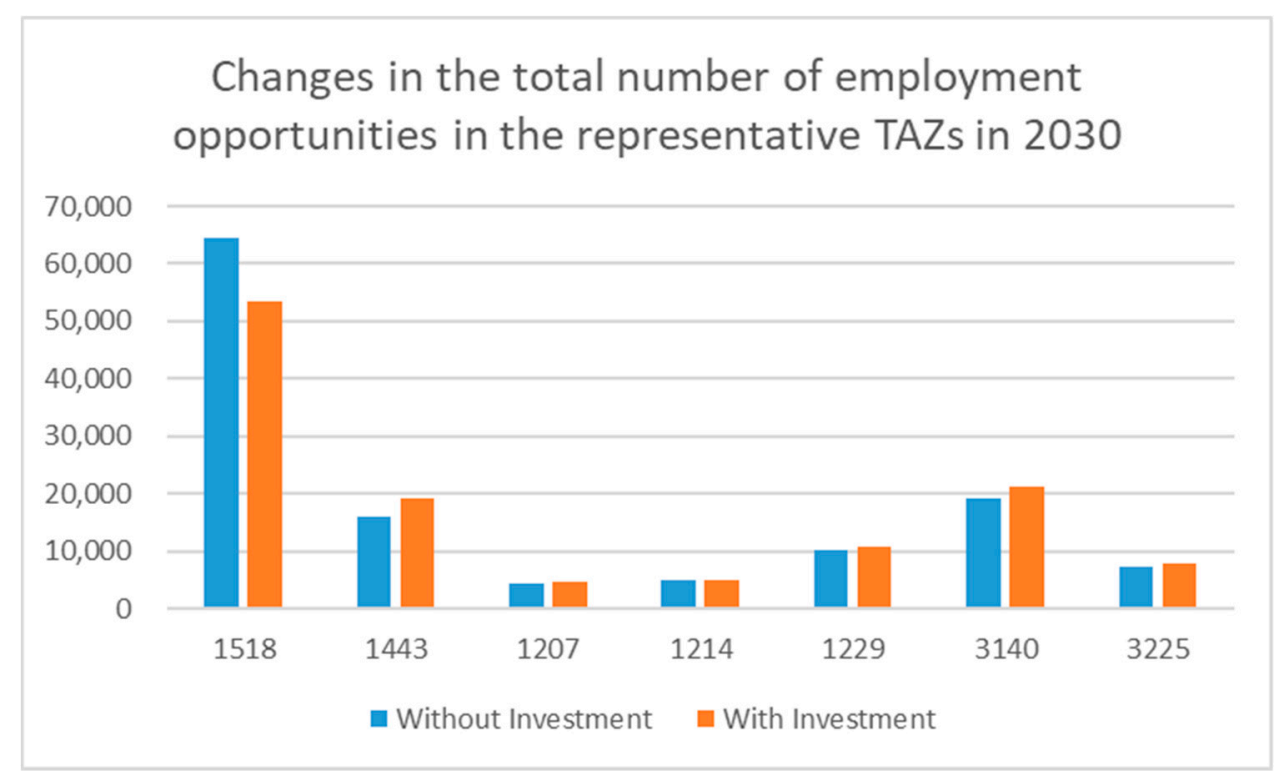

Figure 9. Changes in the total number of employment opportunities in the representative TAZs in 2030. 
Table 4 presents the change in employment opportunities by industry in the representative TAZs. The employment opportunities in Industry-Operation and Government Services in Zone 1518 decrease by 7136 and 3594, respectively, taking up the most part of the employment loses in the zone. It seems that the improvements in accessibility provided by the line enable more people in Zone 1518 to go to work in other zones.

Table 4. Changes in employment opportunities by industries in the representative TAZs in 2030.

\begin{tabular}{cccccccc}
\hline \multirow{2}{*}{ Activity } & \multicolumn{7}{c}{ Changes in Employment Opportunities by Industries in 2030 } \\
\cline { 2 - 8 } & $\mathbf{1 5 1 8}$ & $\mathbf{1 4 4 3}$ & $\mathbf{1 2 0 7}$ & $\mathbf{1 2 1 4}$ & $\mathbf{1 2 2 9}$ & $\mathbf{3 1 4 0}$ & $\mathbf{3 2 2 5}$ \\
\hline Agriculture-Operation & -647 & -46 & 0 & 0 & 0 & 0 & 0 \\
Agriculture-Office Support & 203 & 106 & 0 & 0 & 0 & 0 & 0 \\
Industry-Operation & -7136 & 122 & 18 & 47 & 39 & 110 & -38 \\
Industry-Office Support & -146 & 142 & 0 & 1 & 1 & 1 & 2 \\
Transport and Utility-Operations & 0 & 0 & 3 & 0 & 1 & 2 & 1 \\
Transport and Utility-Office Support & 0 & 3 & 0 & 0 & 0 & 0 & 0 \\
Commerce-Service & 211 & 4 & -5 & -10 & -25 & -41 & 23 \\
Education and Research & 0 & 585 & 77 & 14 & 0 & 328 & 154 \\
Other Institutions & 82 & 101 & 9 & 3 & 62 & 121 & 5 \\
Government Services & -3594 & 2223 & 177 & 6 & 463 & 1354 & 522 \\
Total change & $-11,027$ & 3241 & 279 & 61 & 539 & 1875 & 669 \\
\hline
\end{tabular}

A closer look at the locations of the zones (see Figure 10, where the red solid lines represent the borders of the zones) reveals that Zone 1518 has an obviously larger area than the other zones, e.g., Zone 1443 located in the middle of the figure. This explains partly the huge difference between the numbers for Zone 1518 and those for the other representative zones.

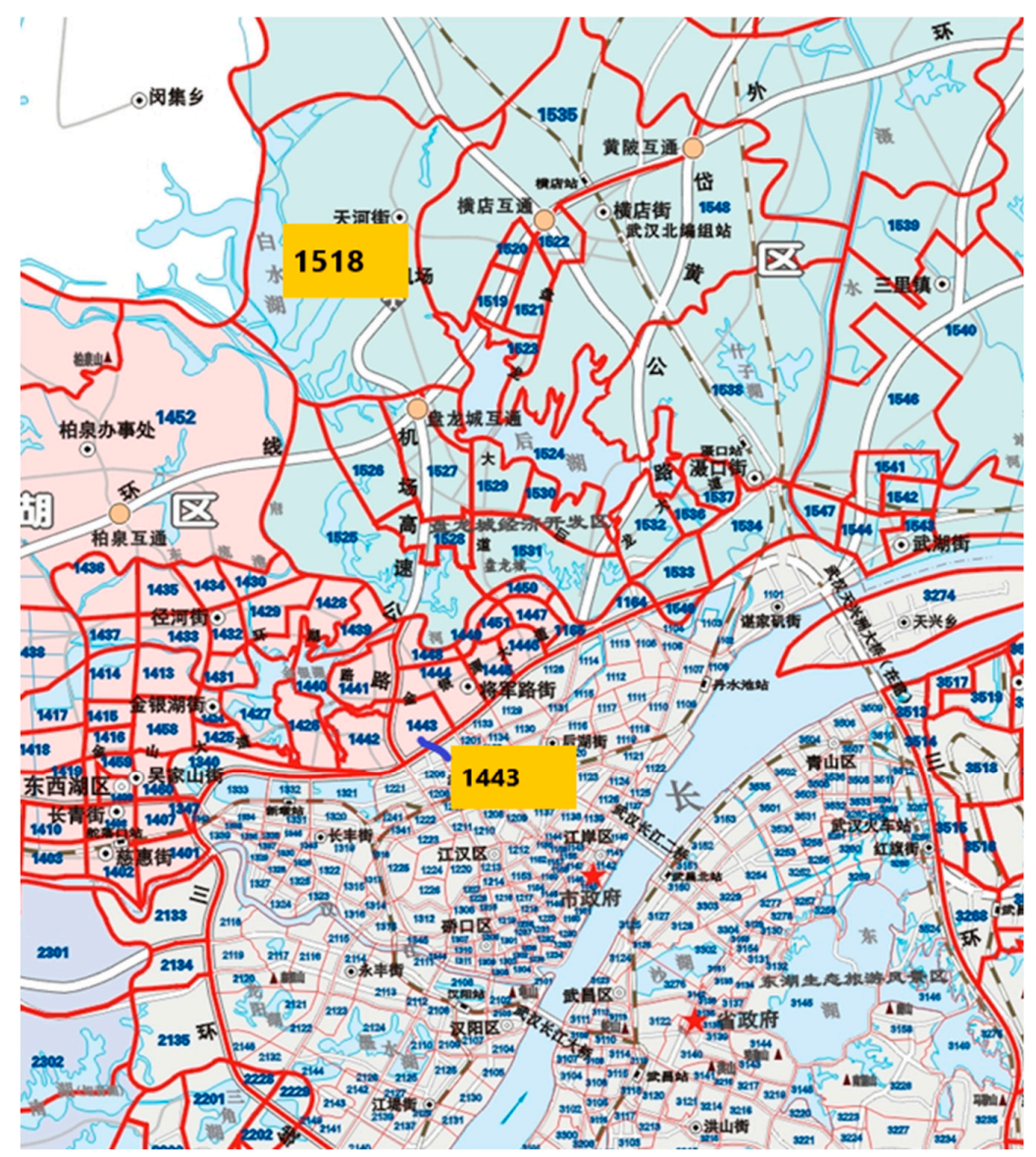

Figure 10. Demonstration of TAZs on the Wuhan city map. 
Table 5 shows a comparison of the effective density under two scenarios of the chosen zones where the representative stations are located. The calculation of the effective density was based on the generalized cost and the number of all employment opportunities for different zones. It can be seen that Zone 1229 has a relatively higher effective density than the other zones, and Zone 1518 has a relatively lower density than the rest. When it comes to the comparison of effective density between the "with investment" and "without investment" scenarios, all zones enjoy an increase of effective density with investment, suggesting a positive effect of investment. To be more exact, the increase of effective density for Zones 1207 and 1214 is the greatest (nearly 1.095), followed by Zones 1229, 3140, 1443, and 3225 (nearly 1.057) and 1518. Even though the employment of Zone 1518 decreases, the effective density of it increases.

Table 5. Comparison of effective density for chosen zones in 2030.

\begin{tabular}{ccccc}
\hline Zone No. & Station Name & $\begin{array}{c}\text { Effective Density } \\
\text { (without } \\
\text { Investment) }\end{array}$ & $\begin{array}{c}\text { Effective Density } \\
\text { (with Investment) }\end{array}$ & $\begin{array}{c}\text { Ratio (with } \\
\text { Investment/without } \\
\text { Investment) }\end{array}$ \\
\hline 1518 & Tianhe International Airport & $1,967,185.691$ & $2,010,089.243$ & 1.021809609 \\
1443 & Changqing Garden & $4,262,896.188$ & $4,510,092.047$ & 1.057987774 \\
1207 & Hankou Railway Station & $5,337,381.411$ & $5,847,937.903$ & 1.095656737 \\
1214 & Wangjiadun East & $5,642,290.155$ & $6,192,421.53$ & 1.097501433 \\
1229 & Xunlimen & $6,094,571.856$ & $6,515,213.463$ & 1.069019058 \\
3140 & Hongshan Square & $5,646,371.625$ & $5,981,496.925$ & 1.059352328 \\
3225 & Optics Valley Square & $4,305,828.006$ & $4,553,116.714$ & 1.057431162 \\
\hline
\end{tabular}

According to Equations (2) and (3) and the agglomeration elasticity by industries in Table 1, the wider benefits for the representative zones due to the agglomeration effect for all the industries were calculated and are shown in Figure 11. The total additional benefit was calculated to be 58.83 million yuan in 2008 yuan. Meanwhile, it seems that the project gives more benefit to the development of the zone with the airport than to that of the zone with the railway station. As can be seen from the figure, Zone 1518 enjoys the highest benefit among the seven representative zones, while Zone 1207 receives the lowest benefit. Zone 1518 aside, due to its huge size compared with the other zones, Zone 1207 still gains less than the other five zones. The impact of the metro line construction on the areas outside of or near the Third Ring Road is greater than that on the areas inside. This may be because the construction of the line greatly improves the accessibility of the suburban areas. On the other hand, the areas near the center of the city have a somewhat better location with relatively better infrastructure, which makes the impact of a line not as obvious.

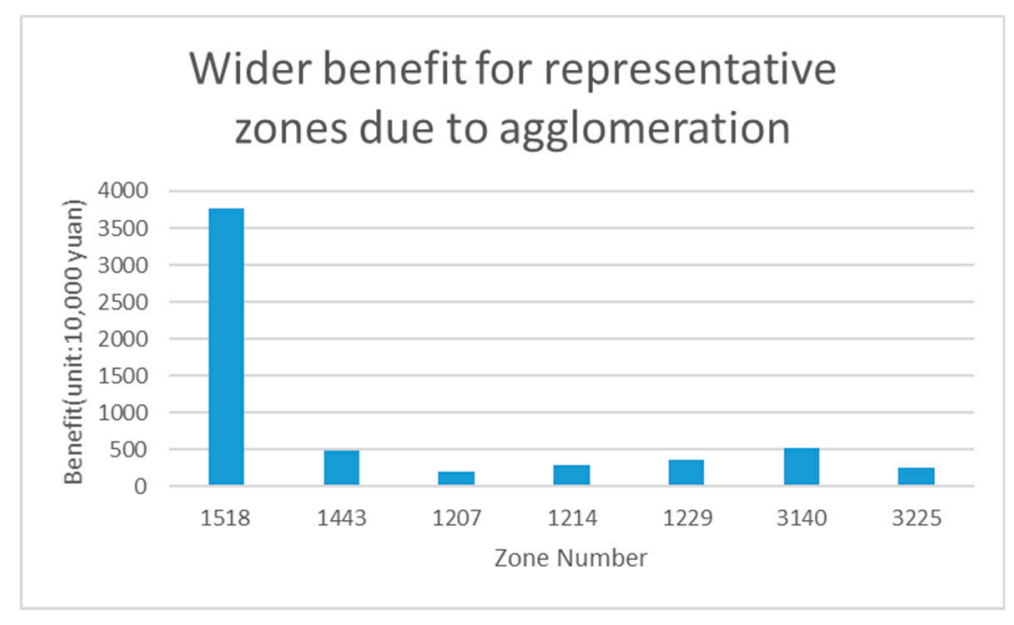

Figure 11. Wider benefit for representative zones due to agglomeration. 


\section{Conclusions and Recommendations}

For the past few decades, cities in China have been undergoing rapid growth in their economy, built environment, and transportation infrastructure. However, the problem of traffic congestion and air pollution has been becoming ever more serious with the expansion of the cities and skyrocketing car ownership. LUTI models, with their capacity for considering the interactions between social/economic development, land use, and transport, could be developed and used to tackle the above issues. They can systematically evaluate the compounded results from various policies related to migration of population, economy, land use, and transport infrastructure, and the resulting land use patterns and urban forms can be explicitly forecasted.

In this paper, we used an integrated land use transport model-the Wuhan PECAS model-to analyze the agglomeration effect of a transport investment project-the Metro Line 2. Generally, the investment exhibits various impacts on different zones and different industries. Although the total number of employment opportunities in different zones may increase or decrease, the effective density for all of them increases. Meanwhile, as the first line to connect the airport with the city, the project benefits the zone with the airport more than it does that with the railway. The results from this study clearly demonstrate that the benefits of metro line construction can be evaluated in a systematic and comprehensive way. With a LUTI model, the WEI (agglomeration effect) besides the user benefit can be analyzed. Also, the distribution effect of the project can be explored, providing a clear picture to the decision-makers when making planning decisions pertinent to specific areas in the city. In light of this, three possible research prospects are recommended:

(1) The estimation of the elasticity of productivity with respect to agglomeration (effective density) for different sectors;

(2) Empirical studies on wider economic benefit assessment in developing countries; and

(3) The inclusion of wider economic benefits in the appraisal framework of transport infrastructure construction.

Author Contributions: Conceptualization, W.W. and M.Z.; methodology, W.W., M.Z. and J.D.H.; software, J.D.H.; validation, W.W. and M.Z.; formal analysis, W.W.; investigation, W.W. and M.Z.; resources, M.Z.; data curation, W.W. and M.Z.; writing—original draft preparation, W.W.; writing—review and editing, W.W. and M.Z.; visualization, W.W.; supervision, M.Z.; project administration, M.Z.; funding acquisition, M.Z.

Funding: This research was funded by a research fund from the WHTPI, a start-up grant from Wuhan University of Technology, and research funds from National Natural Science Foundation of China $(51778510,61603396)$.

Acknowledgments: The authors would like to thank Wuhan Transportation Planning Institute (WHTPI) for their initiatives in integrated land use transport modelling.

Conflicts of Interest: The authors declare no conflict of interest.

\section{References}

1. Department for Transport (DfT). Transport Analysis Guidance (TAG) Unit A2.1 Wider Impacts; DfT: London, UK, 2014.

2. Wangsness, P.B.; Rødseth, K.L.; Hansen, W. A review of guidelines for including wider economic impacts in transport appraisal. Transp. Rev. 2016. [CrossRef]

3. Hunt, J.D.; Simmonds, D.C. Theory and application of an integrated land-use and transport modelling framework. Environ. Plan. 1993, 20, 221-244. [CrossRef]

4. de la Barra, T. Mathematical Description of TRANUS. 2012. Available online: http:/ / www.modelistica.com (accessed on 5 July 2017).

5. Hunt, J.D.; Abraham, J.E. Design and Application of the PECAS Land Use Modelling System. 2003. Available online: http://www.scag.ca.gov/Documents/Design_Application\%20_PECAS.pdf (accessed on 28 October 2017). 
6. Weidner, T.; Hunt, J.D.; Abraham, J.E.; Moeckel, R.; Gregor, B.; Knudson, B. Final calibration of the Statewide Oregon2TM integrated land use-transport model. In Proceedings of the Transportation Research Board 87th Annual Meeting, Washington, DC, USA, 13-17 January 2008.

7. Hunt, J.D.; Weidner, T.; Knudson, R.; Bettinardi, A.; Wardell, E. Applying the SWIM2 integrated model in freight planning in Oregon. In Proceedings of the Transportation Research Board 90th Annual Meeting, Washington, DC, USA, 23-27 January 2011.

8. Gao, S.; Lehmer, E.; Wang, Y.; Mccoy, M.; Johnston, R.A.; Abraham, J.; Hunt, J.D. Developing California integrated land use/transportation model. In Proceedings of the Transportation Research Board 89th Annual meeting, Washington, DC, USA, 10-14 January 2010.

9. Abraham, J.E.; Hunt, J.D.; Wang, W. Generating PECAS base year built form for Clayton County in Atlanta. In Proceedings of the 5th TRB Conference on Innovations in Travel Modeling, Baltimore, MD, USA, 27-30 April 2014.

10. Fuenmayor, G. Building a Spatial Economic Model for Caracas Using PECAS. Ph.D. Thesis, Department of Civil Engineering, University of Calgary, Calgary, AB, Canada, 2016.

11. Mir, M.S.; Krishna Rao, K.V.; Hunt, J.D. Space development modeling of urban regions in developing countries. J. Urban Plan. Dev. 2010, 136, 75-85. [CrossRef]

12. De Jong, G.; Pieters, M.; Daly, A.; Graafland, I.; Kroes, E. Using the Logsum as an Evaluation Measure: Literature and Case Study; RAND Group: Santa Monica, CA, USA, 2005.

13. Lakshmanan, T.R. The broader economic consequences of transport infrastructure investments. J. Transp. Geogr. 2011, 19, 1-12. [CrossRef]

14. Ma, S.; Tang, X.; Ye, J. Logsum difference and nested logit model in traveler benefits estimation. J. Transp. Syst. Eng. Inf. Technol. 2016, 16, 45-50.

15. Zondag, B.; de Jong, G. The development of the TIGRIS XL model: A bottom-up approach to transport, land-use and the economy. Res. Transp. Econ. 2011, 31, 55-62. [CrossRef]

16. Cevero, R.; Landis, J. Twenty years of the Bay Area rapid transit system: Land-use and development impacts. Transp. Res. Part A 1997, 31, 309-333.

17. Pan, H. Rail transit and optimization of spatial structure in metropolitan. Shanghai Urban Plan. Rev. 2007, 6, 37-43. (In Chinese)

18. Pan, H.; Zhang, M. Rail transit impacts on land use. J. Transp. Res. Rec. 2008, 2048, 16-25. [CrossRef]

19. Pan, H.; Chen, G. Rail transit and residential location choice. Urban Plan. Forum 2009, 5, 71-76. (In Chinese)

20. Dube, J.; Theriault, M.; Rosiers, F.D. Commuter rail accessibility and house values: The case of the Montreal South Shore, Canada, 1992-2009. Transp. Res. Part A 2013, 54, 49-66. [CrossRef]

21. Kay, A.I.; Noland, R.B.; Di Petrillo, S. Residential property valuations near transit stations with transit-oriented development. J. Transp. Geogr. 2014, 39, 131-140. [CrossRef]

22. Wu, Q.; Ye, X. Analysis of relationships between urban rail transit accessibility improvement and residential property appreciations. J. Tongji Univ. (Nat. Sci.) 2016, 44, 899-906.

23. SACTRA. Transport and the Economy; SACTRA: London, UK, 1999.

24. Lowry, I.S. A Model of Metropolis; Rand Corp.: Santa Monica, CA, USA, 1964.

25. Hunt, J.D.; Kriger, D.S.; Miller, E.J. Current operational urban land-use transport modelling frameworks: A review. Transp. Rev. 2005, 25, 329-376. [CrossRef]

26. Iacono, M.; Levinson, D.; El-Geneidy, A. Models of transportation and land use change: A guide to the territory. J. Plan. Lit. 2008, 22, 323-340. [CrossRef]

27. Wegener, M. Overview of Land Use Transport Models. In Transport Geography and Spatial Systems; Hensher, D.A., Button, K.J., Eds.; Pergamon/Elsevier Science: Kidlington, UK, 2004; pp. 127-146.

28. Pfaffenbichler, P.; Emberger, G.; Shepherd, S. The Integrated Dynamic Land Use and Transport Model MARS; Networks and Spatial Economics: Berlin, Germany, 2008; ISSN 1566-113X.

29. Feldman, O.; Nicoll, J.; Simmonds, D.; Sinclair, C.; Skinner, A. Use of integrated transportation land use models in the wider economic benefits calculations of transport schemes. In Proceedings of the 87th Annual Meeting of the Transportation Research Board, Washington, DC, USA, 13-17 January 2008.

30. Rodier, C.; Abraham, J.E.; Dix, B.N.; Hunt, J.D. Equity analysis of land use and transport plans using an integrated spatial model. In Proceedings of the 89th Annual Meeting of the Transportation Research Board, Washington, DC, USA, 10-14 January 2010.

31. Graham, D.J. Agglomeration, productivity and transport investment. J. Transp. Econ. Policy 2007, 41, 317-343. 
32. Graham, D.J.; Dender, K.V. Estimating the agglomeration benefits of transport investments: Some tests for stability. Transportation 2011, 38, 409-426. [CrossRef]

33. Hensher, D.A.; Truong, T.P.; Mulley, C.; Ellison, R. Assessing the wider economy impacts of transport infrastructure investment with an illustrative application to the North-West Rail Link project in Sydney. J. Transp. Geogr. 2012, 24, 292-305. [CrossRef]

34. Graham, D.J. Wider Economic Benefits of Transport Improvements: Link between Agglomeration and Productivity, Stage 1 Report; Imperial College London: Centre for Transport Studies: DfT Cite Report, UK, 2005. Available online: https://www.researchgate.net/publication/238775030_Wider_economic_benefits_ of_transport_improvements_link_between_agglomeration_and_productivity_Stage_1_Report (accessed on 24 April 2017).

35. Venables, A.J. Incorporating Wider Economic Impacts within Cost-Benefit Appraisal. OECD International Transport Forum: OECD Publishing, France, 2016. Available online: https://www.oecd-ilibrary.org/ transport/quantifying-the-socio-economic-benefits-of-transport/incorporating-wider-economic-impactswithin-cost-benefit-appraisal_9789282108093-6-en (accessed on 24 April 2017).

36. Legaspi, J.; Hensher, D.; Wang, B. Estimating the wider economic benefits of transport investments: The case of the Sydney North West Rail Link Project. Case Stud. Transp. Policy 2015, 3, 182-195. [CrossRef]

37. Lu, J.; Tao, Z. Trends and determinants of China's industrial agglomeration. J. Urban Econ. 2009, 65, 167-180. [CrossRef]

38. Lin, H.L.; Li, H.Y.; Yang, C.H. Agglomeration and productivity: Firm-level evidence from China's textile industry. China Econ. Rev. 2011, 22, 313-329. [CrossRef]

39. Department for Transport (DfT). Transport, Wider Economic Benefits, and Impacts on GDP; DfT: London, UK, 2005.

40. Graham, D.J.; Melo, P.C. Assessment of wider economic impacts of high speed rail for Great Britain. In Transportation Research Record, 2261; Transportation Research Board: Washington, DC, USA, 2011; pp. 15-24.

41. Hunt, J.D.; Abraham, J.E. PECAS Theoretical Formulation. 2009. Available online: http:/ /www.hbaspecto. $\mathrm{com} /$ pecas/downloads / (accessed on 24 April 2017).

42. Zhong, M.; Hunt, J.D.; Abraham, J.E.; Li, Y.Q.; Li, J.Z.; Yang, W.; Wang, X.Z. A summary of design and development strategies of Wuhan PECAS model. In Proceedings of the World Conference on Transport Research (WCTR), Shanghai, China, 10-15 July 2016. 